\title{
Commentary: Radial artery and bilateral mammary arteries in coronary artery bypass grafting: How much is too much?
}

\author{
Derrick Y. Tam, MD, and Stephen E. Fremes, MD, MSc, FRCSC, FACP, FACC
}

\footnotetext{
From the Division of Cardiac Surgery, Department of Surgery, Schulich Heart Centre, Sunnybrook Health Sciences Centre, University of Toronto, Toronto, Ontario, Canada.

Disclosures: Authors have nothing to disclose with regard to commercial support.

Received for publication Jan 3, 2019; accepted for publication Jan 3, 2019; available ahead of print Feb 7, 2019.

Address for reprints: Stephen E. Fremes, MD, MSc, FRCSC, FACP, FACC, Cardiovascular Surgery, Schulich Heart Centre, Sunnybrook Health Sciences Centre, 2075 Bayview Ave, Room H4 05, Toronto, Ontario M4N 3M5, Canada (E-mail: Stephen.fremes@sunnybrook.ca).

J Thorac Cardiovasc Surg 2019;158:152-3

$0022-5223 / \$ 36.00$

Copyright (c) 2019 by The American Association for Thoracic Surgery

https://doi.org/10.1016/j.jtcvs.2019.01.009
}

Long-term outcomes after coronary artery bypass grafting (CABG) largely relate to complete revascularization and graft patency. Recent changes in guidelines have advocated for the additional use of arterial grafting. In the 2018 European Society of Cardiology/European Association for Cardio-Thoracic Surgery guidelines, the radial artery (RA) is preferable to the saphenous vein (SV) in those with high-grade stenosis (class I level of evidence: B) and bilateral internal mammary arteries (BIMA) in those not at high risk for sternal infection (Class IIa level of evidence: B). ${ }^{1}$ However, the use of a third arterial conduit is less clear. In this issue of The Journal of Thoracic and Cardiovascular Surgery, Formica and colleagues ${ }^{2}$ compare the RA versus the $\mathrm{SV}$ as the third conduit in patients undergoing BIMA grafting. In a propensity score-matched analysis of 190 pairs of patients with 3-vessel coronary artery disease, survival was similar at 5, 10, and 15 years and there was no difference in the hazard ratio (HR), 1.05 (95\% confidence interval [CI], 0.62-1.79; $P=.83$ ). Importantly, there was no difference in early mortality, which was low in both groups. The authors are to be congratulated for their efforts in combining their data-rich surgical registry and linking it to a regional health database system to ascertain late allcause mortality with a median follow-up of 9.2 years. They were able to match 190 of 206 of their patients in the exposure group (BIMA and radial) to a suitable control. Overall survivorship was high in both group at 15 years, approximately $80 \%$, highlighting the importance of durable results with BIMA grafting in a relatively young population (mean age approximately 60 years).

Nonetheless, this study must be interpreted in the context of some important limitations. The results of their study are from a single center, where over $31 \%$ of patients received BIMA grafting during the study period. In contrast, an analysis of the Society of Thoracic Surgeons National Database suggests that $<5 \%$ of CABG procedures performed annually in the United States used BIMA grafting. ${ }^{3}$ This suggests that surgeons at this center might be facile at performing multiple arterial grafting and

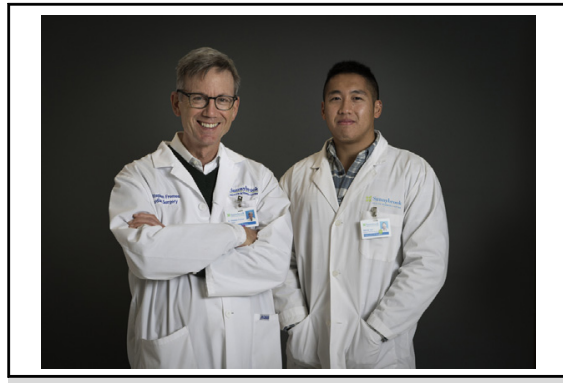

Drs Stephen E. Fremes, MD, MSc, FRCSC, FACP, FACC, and Derrick Y. Tam, MD

\section{Central Message}

No survival benefit was seen with the additional use of a radial artery graft with bilateral internal mammary artery grafting in a small propensity score matched analysis of 190 patient-pairs at a median of a 9.2-year follow-up.

See Article page 141

this might be particularly important because recent work by Gaudino and colleagues showed a volume-outcome relationship in BIMA grafting and that surgeon experience might have an effect on late outcomes. ${ }^{4}$ In this series of patients, the RA was only grafted to the right coronary artery when there was a critical stenosis defined as $\geq 90 \%$ and to the circumflex territory when stenosis severity was $\geq 70 \%$. However, there is evidence to suggest that the use of $\geq 70 \%$ might be too lax and a gradient effect exists such that RA patency is associated with higher degree of native vessel stenosis. ${ }^{5,6}$ It is usual to direct both mammary grafts to the left coronary circulation ${ }^{7}$ but in this study, the right mammary artery was directed to the right coronary in $3.7 \%$ of the SV graft patients and in $15.8 \%$ of the RA graft patients. This study only reported late survival; the ascertainment of nonfatal outcomes such as stroke, myocardial infarction, and repeat revascularization would be informative. Finally, there was no difference in survival in a relatively small sample size; the number of patients at risk at 15 years of follow-up was quite low in the BIMA and radial group. Findings from the Arterial Revascularization Trial showed no difference in mortality at 10 years in $>3000$ patients randomized to BIMA or single internal mammary artery grafting strategies ${ }^{8}$; the benefits of arterial grafting might not be realized until the 
second decade and highlights the importance of long follow-up.

The additional use of the RA as the secondary arterial graft after the left internal mammary artery to the left anterior descending artery has recently been investigated. A recent meta-analysis of patient-level data from randomized clinical trials showed that the use of the RA over the SV in addition to the left internal mammary artery to left anterior descending reduced the late composite of death, myocardial infarction, and repeat revascularization (HR: $0.67,95 \% \mathrm{CI}$ : $0.49,0.90$ ) but not all cause mortality (HR: $0.90,95 \% \mathrm{CI}$ : $0.59,1.41) .{ }^{9}$ However, whether the RA should be added to a patient undergoing BIMA grafting remains less certain. Findings from this study are consistent with recent work from our group showing no difference in late mortality in 2789 propensity score matched pairs comparing 3 arteries vs 2 arteries (HR: 1.08 [95\% CI, 0.90-1.29], mean/ maximum follow-up 4.2/8.5 years). ${ }^{10}$ On the contrary, a meta-analysis of 8 propensity score-matched observational studies suggests that 3 arterial grafts were associated with a lower risk of late death (HR, 0.80; 95\% CI, 0.75-0.87) $)^{11}$ compared with use of 2 arteries. Similarly, a metaanalysis of randomized clinical trials and observational studies suggested that late mortality was modestly reduced with total arterial revascularization compared with CABG with 2 arteries (incident rate ratio, $0.85 ; 95 \% \mathrm{CI}$, 0.73-0.99). ${ }^{12}$

In this small study of 190 pairs of patients, there did not appear to be a benefit of the additional use of a RA with a BIMA grafting strategy. However, there was no short-term harm in this strategy of the additional use of a radial graft. Perhaps results might be further optimized through heart team discussions regarding conduit selection and ensuring optimal postoperative medical therapy. Nonetheless, further follow-up in a larger sample of patients is required to determine the benefits of 3 arteries versus 2 arteries and to address whether a third arterial graft is really "too much" in CABG.

\section{References}

1. Neumann FJ, Sousa-Uva M, Ahlsson A, Alfonso F, Banning AP, Benedetto U, et al. 2018 ESC/EACTS guidelines on myocardial revascularization. Eur Heart J. 2019;40:87-165

2. Formica F, D'Alessandro SD, Singh G, Ciobanu AM, Messina LA, Scianna S, et al. The impact on late survival of the radial artery or the saphenous vein in addition to the bilateral internal mammary arteries. A propensity analysis J Thorac Cardiovasc Surg. 2019;158:141-51.

3. D'Agostino RS, Jacobs JP, Badhwar V, Fernandez F, Paone G5, Wormuth DW, et al. The Society of Thoracic Surgeons adult cardiac surgery database: 2018 update on outcomes and quality. Ann Thorac Surg. 2018;105:15-23.

4. Gaudino M, Bakaeen F, Benedetto U, Rahouma M, Di Franco A, Tam DY, et al. Use rate and outcome in bilateral internal thoracic artery grafting: insights from a systematic review and meta-analysis. J Am Heart Assoc 2018; 7:e009361.

5. Miwa S, Desai N, Koyama T, Chan E, Cohen EA, Fremes SE, et al. Radial artery angiographic string sign: clinical consequences and the role of pharmacologic therapy. Ann Thorac Surg. 2006;81:112-8; discussion: 119.

6. Desai ND, Naylor CD, Kiss A, Cohen EA, Feder-Elituv R, Miwa S, et al. Impact of patient and target-vessel characteristics on arterial and venous bypass graft patency: insight from a randomized trial. Circulation. 2007; 115:684-91.

7. Taggart DP, Altman DG, Gray AM, Lees B, Gerry S, Benedetto U, et al. Randomized trial of bilateral versus single internal-thoracic-artery grafts. N Engl J Med. 2016;375:2540-9.

8. Freemantle N, Milojevic M, Lim S, Fremes S, Pagano D. 32nd EACTS annual meeting clinical trials update: ART, IMPAG, MITRA-FR and COAPT. Eur $J$ Cardiothorac Surg. 2019;55:186-90.

9. Gaudino M, Benedetto U, Fremes S, Biondi-Zoccai G, Sedrakyan A, Puskas JD, et al. Radial-artery or saphenous-vein grafts in coronary-artery bypass surgery. $N$ Engl J Med. 2018;378:2069-77.

10. Rocha RV, Tam DY, Karkhanis R, Nedadur R, Fang J, Tu JV, et al. Multiple arterial grafting is associated with better outcomes for coronary artery bypass grafting patients. Circulation. 2018;138:2081-90.

11. Gaudino M, Puskas JD, Di Franco A, Ohmes LB, Iannaccone M, Barbero U, et al. Three arterial grafts improve late survival: a meta-analysis of propensitymatched studies. Circulation. 2017;135:1036-44.

12. Yanagawa B, Verma S, Mazine A, Tam DY, Jüni P, Puskas JD, et al. Impact of total arterial revascularization on long term survival: a systematic review and meta-analysis of 130,305 patients. Int J Cardiol. 2017;233:29-36. 